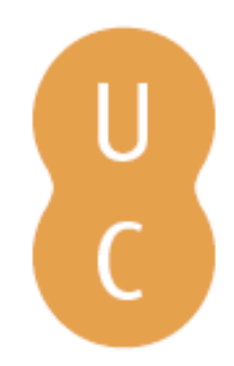

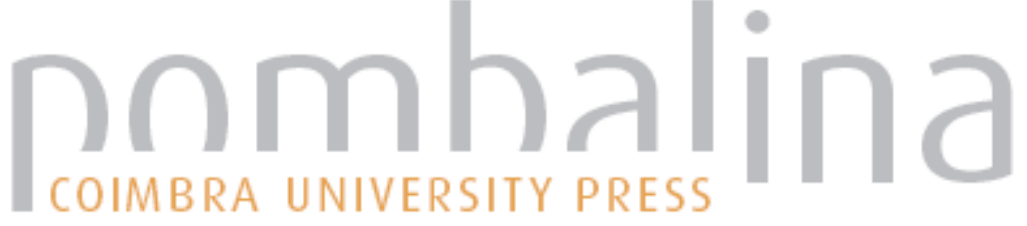

\section{O elemento feminino no teatro jesuítico em Portugal no século XVI}

\author{
Autor(es): $\quad$ Melo, António Maria Martins \\ Publicado por: Imprensa da Universidade de Coimbra \\ URL \\ persistente: \\ URI:http://hdl.handle.net/10316.2/32341 \\ DOI: \\ DOI:http://dx.doi.org/10.14195/978-989-26-0482-4_11
}

Accessed : $\quad$ 26-Apr-2023 14:50:16

A navegação consulta e descarregamento dos títulos inseridos nas Bibliotecas Digitais UC Digitalis, UC Pombalina e UC Impactum, pressupõem a aceitação plena e sem reservas dos Termos e Condições de Uso destas Bibliotecas Digitais, disponíveis em https://digitalis.uc.pt/pt-pt/termos.

Conforme exposto nos referidos Termos e Condições de Uso, o descarregamento de títulos de acesso restrito requer uma licença válida de autorização devendo o utilizador aceder ao(s) documento(s) a partir de um endereço de IP da instituição detentora da supramencionada licença.

Ao utilizador é apenas permitido o descarregamento para uso pessoal, pelo que o emprego do(s) título(s) descarregado(s) para outro fim, designadamente comercial, carece de autorização do respetivo autor ou editor da obra.

Na medida em que todas as obras da UC Digitalis se encontram protegidas pelo Código do Direito de Autor e Direitos Conexos e demais legislação aplicável, toda a cópia, parcial ou total, deste documento, nos casos em que é legalmente admitida, deverá conter ou fazer-se acompanhar por este aviso. 
Sebastiāo Tavares de Pinho

Coordenação

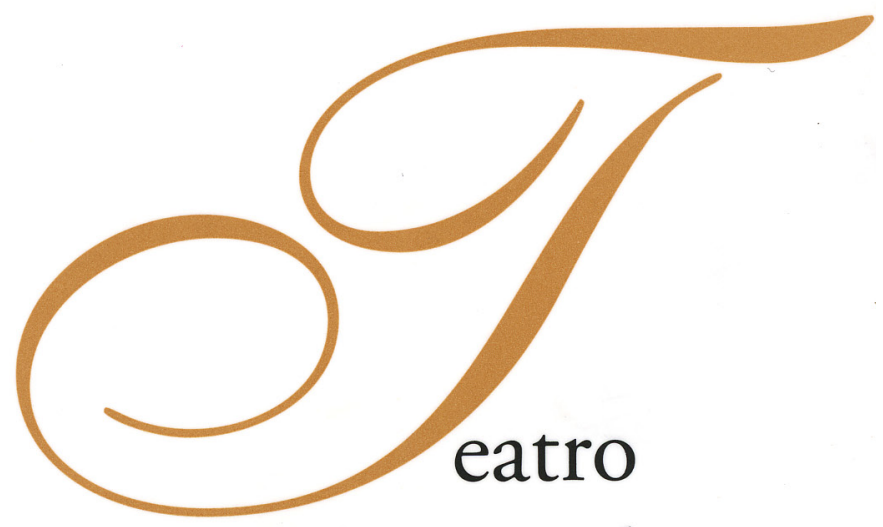

Neolatino em Portugal

no Contexto da Europa

450 Anos

de Diogo de Teive

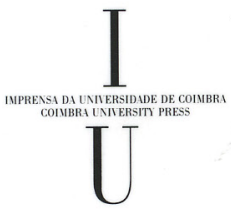

- COIMBRA 2006 
(Página deixada propositadamente em branco) 
C

U

M

E

$\mathrm{N}$

T

0

S

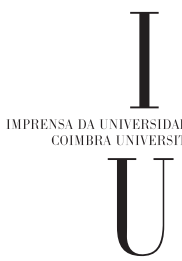




\section{COORDENAÇÃO EDITORIAL}

Imprensa da Universidade de Coimbra

URL: http//www.imp.uc.pt

\section{CONCEPÇÃo GRÁFICA}

António Barros

PRÉ-IMPRESSÃo

António Resende

Imprensa da Universidade de Coimbra

EXECUÇÃo GRÁFICA

SerSilito - Maia

ISBN

$972-8704-75-5$

DEPÓSITO LEGAL

(C) Junho 2006, Imprensa da Universidade de Coimbra

OBRA PUBLICADA COM O FINANCIAMENTO DE:

Centro de Estudos Clássicos e Humanísticos

FCT Fundação para a Ciência e a Tecnologia

MINISTÉRIO DA CIÊNCIA, TECNOLOGIA E ENSINO SUPERIOR Portugal

OBRA PUBLICADA COM O APOIO DE:

FCT: Fundação para a Ciência e Tecnologia • Ministério da Ciência e do Ensino Superior Apoio do Programa Operacional para a Ciência, Tecnologia, Inovação do III Quadro Comunitário de Apoio 
O TEATRO NeOlatino EM PORTUGal NO CONTEXTO DA EUROPA

450 AnOs DE DIOGO DE TEIVE 
(Página deixada propositadamente em branco) 
António Maria Martins Melo

Universidade Católica Portuguesa

O ELEMENTO FEMININO NO TEATRO JESUÍTICO

EM PORTUGAL NO SÉCULO XVI

A Companhia de Jesus é uma ordem religiosa masculina, sem ramo feminino $^{(1)}$. Este facto, que os tempos têm confirmado, aliado a algumas deliberações de Inácio de Loiola, tem projectado sobre a Companhia uma imagem de misoginia. Para tal ideia, ocupa lugar de relevo a comparação do demónio à mulher, que o fundador apresenta nos Exercícios Espirituais, nas regras para o maior discernimento de espíritos: "O inimigo porta-se como uma mulher: fraco ante a resistência, e forte, ante a condescendência. Porque assim como é próprio da mulher, quando briga com um homem, perder ânimo e pôr-se em fuga, quando o homem lhe mostra rosto firme; e, pelo contrário, se o homem começa a fugir e perde a coragem, a ira, a vingança e a ferocidade da mulher é muito grande»(2). A importância deste pensamento deve-se à particularidade de este ser o livro fundacional da

(1) A única mulher jesuíta foi D. Joana de Áustria, filha de Carlos V de Espanha e de Isabel de Portugal. Casada com o malogrado príncipe D. João Manuel, filho de D. João III e de Catarina da Áustria, daria à luz o futuro rei D. Sebastião. Após decisão tomada em Outubro de 1554, Inácio de Loiola aceita admiti-la a "título experimental» e em segredo absoluto. Recordemos que já tinha havido a tentativa de Isabel Roser, natural de Barcelona, se transformar na primeira mulher jesuíta, pretensão negada pelo fundador da Companhia em missiva datada do primeiro dia do mês de Outubro de 1546. JEAn LACOUTure, Os Jesuítas - 1. A Conquista, tradução de Maria Fernanda Gonçalves Azevedo, Lisboa, 1993, pp. 187-215; HUGO RAHNER, Ignace de Loyola et les femmes de son temps, Paris, 1964, pp. 104-110.

(2) INÁCIO DE LOIOLA, Exercícios Espirituais, tradução do autógrafo espanhol por Vital Cordeiro Dias Pereira, S. J., organização e notas por F. de Sales Baptista, S. J., Braga, 31999 , pp. 167-168, n. ${ }^{\circ} 325$. 
Companhia. Nasceu de uma experiência mística vivida numa gruta em Manresa, junto ao rio Cardoner, em Agosto de 1522. A sua última redacção terá ocorrido quase vinte anos mais tarde, em 1541.

Embora tenha sido esta a visão a prevalecer na Ratio, é bom recordar que Inácio de Loiola trocou abundante correspondência não só com damas de estirpe nobre mas também com as de origem mais humilde. Desse universo nos dá conta a obra do Padre Hugo Rahner, Inácio de Loiola e as mulheres do seu tempo. Mas deste assunto ocupar-nos-emos mais tarde. De momento, e porque a nossa reflexão tem por objecto as realizações teatrais desenvolvidas pelos jesuítas nos seus colégios, em Portugal, durante o século XVI, uma actividade profundamente influenciada pelos autores clássicos latinos, afigura-se-nos prudente algumas palavras introdutórias acerca das primeiras manifestações desta reiterada repulsa mórbida do homem às mulheres.

Tema caro à literatura ocidental, é em Hesíodo que se encontra o seu primeiro testemunho. Com efeito, a história de Pandora, narrada na Teogonia (vv. 565-593) e nos Trabalhos e Dias (vv. 50-99), explica a origem do sofrimento de que a humanidade padece. Perspectiva semelhante se apresenta no fr. 7 de Semónides de Amorgos, datado provavelmente da primeira metade do século VII a. C., e conservado na Antologia de Estobeu (séc. V d. C.). Numa perspectiva de entretenimento, com sabor lúdico, este autor da poesia arcaica grega traça-nos dez retratos femininos, todos eles indesejáveis, excepto um: o da mulher da raça da abelha, ela que dá felicidade ao marido, sendo a única que não merece reprimenda(3). Na Comédia grega abundam os dislates contra as mulheres, nomeadamente em algumas comédias de Aristófanes: a Lisistrata, As mulheres que celebram as Tesmofórias ${ }^{(4)}$ ou em

(3) Vide Francisco ReBelo GONÇALVES, "Simónides de Amorgo, Sátira contra as Mulheres. Notícia literária, tradução do texto grego e comentário filológico", in: FRANCISCO REBELO GONÇALVES, Obra Completa, Vol. I, Lisboa, 1995, pp. 5-69, especialmente p. 41; MARIA FERNANDA BRASETE, "A crítica às mulheres no fr. 7 de Semónides de Amorgos" in: CARLOS DE Miguel MORA (coord.), Sátira, paródia e caricatura: da Antiguidade aos nossos dias, Aveiro, Universidade, 2003, pp. 39-56.

(4) Desta comédia se transcreve uma passagem exemplificativa (vv. 384-405), que tem a particularidade de transferir para a tragédia euripidiana o hábito de dizer mal das mulheres: 
As mulheres na Assembleia. Mas também na tragédia é possível encontrar indícios de espírito semelhante: Creonte, em face da argumentação de Hémon, seu filho, que faz a apologia de uma governação em sintonia com o povo e as leis divinas, para salvar Antígona, atira ao rosto de seu filho palavras ignominiosas que jamais algum homem grego esperaria ouvir: «Tu, que és escravo de uma mulher, não estejas com blandícias»(5).

A misoginia foi igualmente tema versado na literatura latina. Célebre havia de ficar o adágio virgiliano Varium et mutabile / Semper femina!...(6) Naturalmente, os humanistas do Renascimento dariam continuidade a este pensamento. Uma das obras mais representativas desta corrente de opinião é a Silua Nuptialis (1516), do jurista italiano João Nevizano, onde se inspirou Lopo Serrão, para escrever principalmente os Cantos VIII e XIII do seu Poema da Velbice ${ }^{(7)}$.

"Mas há já muito tempo que eu - pobre de mim! — fervo de nos ver enxovalhadas por Eurípides, esse filho de uma hortaliceira, e de ouvir toda a casta de injúrias. Haverá algum insulto com que esse tipo nos não tenha brindado? E calúnias? Seja onde for, desde que haja uma meia dúzia de espectadores, actores e coros, lá começa ele a chamar-nos levianas, doidas por homens, bêbadas, traidoras, tagarelas, uns zeros, a desgraça completa dos maridos. De tal maneira que eles, mal saem do teatro, põem-se a olhar para nós com desconfiança e logo a ver se descobrem algum amante escondido em casa. Já não podemos fazer nada do que fazíamos antes, tais foram as misérias que esse fulano ensinou aos nossos maridos. Assim se uma mulher entrelaça uma coroa, pensam que está apaixonada; se, na lida da casa, deixa cair qualquer coisa, o marido põe-se a perguntar: "Em quem estavas tu a pensar, quando deixaste cair a panela? No hóspede de Corinto, não pode deixar de ser"”. ARISTÓFANES, As mulheres que celebram as Tesmofórias, introdução, versão do grego e notas de Maria de Fátima de Sousa e Silva, Coimbra, ${ }^{2} 1988$, pp. $63-64$.

(5) V. 756: SÓFOCles, Antígona, introdução, versão do grego e notas de Maria Helena da Rocha Pereira, Coimbra, ${ }^{2} 1987$, p. 70 . Sintomática ainda a ausência da mulher nos trinta retratos definidos por Teofrasto nos Caracteres, a que correspondem outros tantos defeitos da natureza humana. MARIA DE FÁTIMA SILVA, "Dinheiro e sociedade (Teofrasto, Caracteres)», in: CARlos DE Miguel MORA (coord.), Sátira, paródia e caricatura ... cit., pp. 91-104, especialmente pág. 92. Ainda a propósito da misoginia helénica, vide ANTÓNIO FREIRE, Humanismo Clássico, Braga, ${ }^{2} 1996$, pp. 75-88.

(6) VIRGílio, Eneida, IV.569-570. Frases com pensamento idêntico podem ler-se em Catulo (Carmina, LXX), em Propércio (III.19), em Ovídio (Amores, III. 1-16; Arte de Amar, II.372-382) ou em Séneca (tragédia Fedra, vv. 559-564). A propósito da presença feminina na obra de Séneca, vide MARIA CRISTINA PIMENTEL, «Estoicismo e figuras femininas em Séneca», Brotéria, 158 (2004) 251-268.

(7) Vide Sebastião TAVARES De PINHO, O poema da Velhice de Lopo Serrão, introdução, texto e aparato crítico, tradução e notas, Coimbra, 1987, pp. 220-225. 
O humanista valenciano Luís Vives, no De institutione foeminae christianae, um tratado de educação feminina com grande difusão no século XVI, não se coibiu de escrever que a formação moral da mulher se alcança com um número reduzido de preceitos, pois é pertença exclusiva da mulher a pudicícia; recomendava, ainda, que a donzela se fizesse acompanhar sempre pela mãe, ainda que permanecesse em casa; aí deve estar recatada do mundo, conhecida de poucos, pois a vida em sociedade é ocasião permanente de maldades e crimes ${ }^{(8)}$.

Portugal assistia, impotente, a momentos de aguda crise familiar: a ausência prolongada do chefe de família, motivada pelo afã das descobertas, conduziu à dissolução de costumes. Houve manifestações de bigamia e elevou-se assustadoramente o número de meninos enjeitados e órfãos ${ }^{(9)}$. A Igreja portuguesa vivia afogada pelas preocupações mundanas, como denuncia André de Resende no sínodo eborense de $1534^{(10)}$; os sacerdotes

(8) Vide J. MANUEL RODRÍGUEZ PEREGRINA, «Mujer, humanismo y sociedad en la Granada del XVI», Florentia Iliberritana, 4-5 (1993-1994) 487-507, especialmente 488-489.

(9) Cf. Johquim Romero magalhães, "A Sociedade», in: História de Portugal, direcção de José Mattoso, Vol. III - «No Alvorecer da Modernidade (1480-1620)», Lisboa, 1993, especialmente pp. 469-475. A propósito, vide RENÉ P. GARAY, "Proto-feminismo no Auto da Índia de Gil Vicente», Brotéria, 158 (2004) 479-486.

(10) «Também a Igreja se prostitui quando, por empenhos, por dinheiro, por favores, por simpatia ou por qualquer defeito moral, mercadeja com gente indigna as funções sagradas, que não podem ser coisa venal, para já não falar em outras formas de prostituição que o mundo bem conhece e que, neste momento, melhor me parece silenciar»: SEBASTIÃO TAVARES DE PINHO, "André de Resende e o Cardeal-Infante D. Afonso: em torno do sermão pregado no sínodo de Évora de 1534”, Eborensia, 1-2 (1988) 66. Ao humanista eborense, religioso dominicano, há-de impor-se, contudo, um certo comedimento, deixando que seja a própria Igreja a corrigir tais abusos, como escreve no Aegidius Scallabitanus: «- Ou melhor — acrescentei -: para não caíres em erro, deves é dizer que "possui para cima de trinta»! Sobre estes assuntos, no entanto, é mais do que aconselhável não murmurar sequer. Esta situação abusiva aguarda a intervenção do braço sinodal, o que acontecerá em Trento - talvez até já tenham começado as sessões - sob a direcção do actual Pontífice Máximo, Júlio III, pois que esta questão tem sido objecto de repetidas queixas por parte de muitos doutoresn: VIRGínIA SOARES PEREIRA, Aegidius Scallabitanus. Um diálogo sobre Fr. Gil de Santarém, estudo introdutório, edição crítica, tradução e notas, Lisboa, 2000, p. 312. Para mais pormenores, vide SEBASTIÃO TAVARES DE PINHO, "André de Resende: o manuscrito do sermão do Sínodo de Évora (1534) e outros autógrafos", in: Cataldo E André de Resende: Congresso Internacional do Humanismo Português (Coimbra-Lisboa-Évora, 25 a 28 de Outubro de 2000), Lisboa, 2002, pp. 219-256. Para a transcrição do texto latino do sermão, vide ISAÍAS DA ROSA PEREIRA, "Sínodo diocesano de Évora de 1534", Anais da Academia Portuguesa de História, II série, 20 (1971) 171-232; JOAQUIm CHORÃo LAVAJO, "André de Resende e a História Religiosa de Portugal", in: Cataldo E André de Resende... cit., pp. 172-173. Testemunho idêntico pode ler-se em ROQUE DE ALMEIDA, Para 
padeciam de uma vida moral censurável, a ponto de Fr. Bartolomeu dos Mártires, recomendar, nas Petições $(1562)^{(11)}$, que «se renovem as decisões dos concílios e as determinações contra os concubinatários»(12). E acrescentava: "que os sacerdotes não prestem serviço a ninguém em actividades menos decentes"(13). No Estímulo de Pastores, obra redigida durante a última fase dos debates conciliares (1561-1563)(14), o Arcebispo de Braga parece retomar este assunto, a propósito da solicitude digna de um bispo. Segundo ele, para se «impedir que o tropel das preocupações e negócios irrompa com repetidos golpes contra a porta do coração e perturbe o sossego da oração e da santa união com Deus», a primeira coisa a fazer é «apartar o coração do amor sensual das criaturas: deita fora os amores sensuais, e ver-te-ás livre de perturbações. Não ames nem desejes nada que não seja em Deus e por amor de Deus, e nenhuns cuidados te afligirão, nem te afastarão de

ler a História da Igreja em Portugal, Porto, 1996, pp. 75-76. Acerca da presença portuguesa no Concílio de Trento, vide Fortunato De Almeida, História da Igreja em Portugal, Porto, Vol. II, 1968, pp. 531-534, que nos dá conta das sessões em que se tratou a questão da residência dos bispos; DAVID SAMPAIO BARBOSA, "Portugal em Trento: Uma presença discreta", Lusitania Sacra, 2. ${ }^{a}$ série, 3 (1991) 11-38; JOSÉ DE CASTRO, "Os Portugueses em Trento», Lumen, 25 (1961) 739-762; para o ambiente que marcou o acolhimento, entre nós, das primeiras orientações conciliares sobre matéria pastoral, vide AMÉLIA M. POLÓNIA DA SILVA, "Recepção do Concílio de Trento em Portugal: as normas enviadas pelo Cardeal Henrique aos Bispos do reino, em 1553", Revista da Faculdade de Letras — História, Porto, II série, 7 (1990) 133-143.

(11) Alguns extractos podem ser lidos em Documenta Bartholomaeana Tridentina. Intervenções conciliares, leitura e tradução de Aires A. Nascimento e Arnaldo do Espírito Santo, introdução de Fr. Raul A. Rolo, O.P., Braga, 1990.

(12) Na Autobiografia de Santo Inácio de Loiola, que o P. Luís Gonçalves da Câmara acabou de redigir em Génova, no mês de Dezembro de 1555, já se regista idêntica preocupação em orientar os costumes em Azpeitia, aquando da sua passagem por ali em 1535: "Había allá otro abuso, que consistía en lo siguiente: en aquel país es costumbre que las muchachas vayan siempre con la cabeza descubierta y que no se la cubran hasta que se casen. Pero hay muchas que se hacen concubinas de los sacerdotes y de otros hombres y les son fieles como si fuesen sus mujeres. Y esto es tan frecuente, que las concubinas no tienen vergüenza en decir que se han cubierto la cabeza por alguno; y por tales son conocidas": El peregrino. Autobiografía de San Ignacio de Loyola, introducción, notas y comentario por Joseph M. ${ }^{a}$ Rambla Blanch, S. J., Bilbao y Santander, ${ }^{4} 2003$, p. 88.

(13) Ibid., p. 37.

(14) A 26 de Janeiro de 1564, pela bula Benedictus Deus, Pio IV daria aprovação a todos os decretos conciliares. O Concílio foi convocado por Paulo III e os trabalhos iniciaram-se, com algum atraso, a 13 de Dezembro de 1545, tendo sido suspensos a 3 de Fevereiro de 1548, numa altura em que o concílio já decorria em Bolonha. De Junho de 1551 a 28 de Abril de 1552, os trabalhos conciliares regressam a Trento, agora sob o patrocínio de Júlio III. 
Deus»(15). Para o bracarense, a par da integridade moral, interessava-lhe propiciar uma sólida formação intelectual ao clero, co-responsável com o bispo no bom andamento da igreja local e diocesana, como indicia esta afirmação registada nas actas conciliares: «Se se não começar pelo exame dos bispos e pela instituição dos seminários, não sei por onde iniciar a reforma, pois estas hão-de ser os dois pilares dela"(16). A esta luz se compreende a fundação do Seminário de S. Pedro, em 1569; nove anos antes, o Arcebispo já havia confiado o Colégio de S. Paulo à Companhia de Jesus(17).

Torna-se clara, deste modo, a importância de um dos vectores fundamentais da intervenção dos jesuítas no âmbito da Reforma Católica: a formação moral e intelectual do clero. Mas também à juventude iria oferecer uma educação humanista dentro dos princípios da ortodoxia católica.

À luz destes factores se deve compreender a intervenção da Companhia de Jesus, mormente as finalidades didácticas da actividade dramática desenvolvida nos seus colégios em Portugal e por toda a Europa(18).

(15) BARTOlOMEU dos MÁRTIREs, Estímulo de Pastores, tradução portuguesa por P. José Barbosa Pinto, S. J. e P. António Freire, S. J., introdução de P. Fr. Raul A. Rolo, O.P., Braga, 1981, p. 149. Para uma análise circunstanciada desta obra, vide DAVID SAMPAIO BARBOSA, "Stimulus Pastorum: texto e contexto de uma proposta de renovação", Lusitania Sacra, 2. série, 15 (2003) 15-41.

(16) RAUl De Almeida Rolo, Bartolomeu dos Mártires. Obra social e educativa, Braga, 1979, p. 49; DAVID SAMPAIO BARBOSA, "Stimulus Pastorum..." cit., p. 26; Documenta Bartholomaeana Tridentina... cit., p. 37.

(17) Para mais pormenores, vide RAUl DE ALMEIDA ROLO, Bartolomeu dos Mártires. Obra social... cit., p. 146.

(18) Sobre a acção cultural da Companhia de Jesus em Portugal, vide ANTÓNIO LOPES, "A educação em Portugal de D. João III à expulsão dos jesuítas, em 1759", Lusitania Sacra, 2. ${ }^{a}$ série, 5 (1995) 13-41. Apesar da dispersão dos missionários pelos novos mundos, a unidade manteve-se e fortalecia-se graças, sobretudo, a uma meticulosa correspondência que assume a feição de relatórios circunstanciados das viagens que empreendiam e dos problemas que enfrentavam em terra de missão: JOÃO PEDRO FERRO, "A epistolografia no quotidiano dos missionários jesuítas nos séculos XVI e XVII", Lusitania Sacra, 2. ${ }^{a}$ série, 5 (1995) 137-158. Na oitava parte das Constituições escreve-se: "Concorrerá também de maneira muito especial para esta união a frequente correspondência epistolar entre súbditos e Superiores, com o intercâmbio de informações entre uns e outros, e o conhecimento das notícias e comunicações vindas das diversas partes. Este encargo pertence aos Superiores, em particular ao Geral e aos Provinciais. Eles providenciarão para que em cada sítio se possa saber o que se faz nas outras partes, para consolação e edificação mútuas em Nosso Senhor." INÁCIO DE LOIOLA, Constituições da Companhia de Jesus... cit., p. 176, n. ${ }^{\circ} 673$. 
Vai ocupar-se esta nossa reflexão de dois mestres jesuítas que leccionaram aqui em Coimbra, no Real Colégio das Artes: de Miguel Venegas e do seu discípulo, Luís da Cruz. Podem considerar-se os mais lídimos representantes do teatro escolar dos jesuítas em Portugal, com importantes repercussões a nível europeu.

Miguel Venegas, natural de Ávila, estreou a tragédia Achabus em 1562, no Real Colégio das Artes, pouco tempo antes de partir para Roma, a 6 de Novembro. Inspira-se sobretudo no Primeiro Livro do Reis (17-19 e $21-22)^{(19)}$.

Sob o reinado de Acab, Israel vive um período de grande prosperidade económica graças, sobretudo, a uma política de proximidade com os Fenícios. Esta amizade consolida-se com o casamento do soberano com Jezabel, filha de Etbaal, rei e sumo sacerdote de Sídon. Com esta união se protegia a ascensão do culto a Baal, divindade fenícia, pois grande era a influência da rainha junto do rei. Mas a idolatria de Israel viria a ser castigada com uma prolongada estiagem, sinónimo de fome. Na verdade, Acab havia ignorado os avisos do profeta Elias.

Três anos volvidos, regressa o profeta à presença do rei, procurando pôr termo ao castigo divino e, simultaneamente, desencadear uma perseguição aos falsos profetas. A acção dramática inicia-se precisamente com o regresso de Elias, do exílio. Confiante na protecção divina, o profeta demanda Acab, auxiliado pelo servo Abdias. Inesperadamente, dá-se o reencontro, marcado por um aceso debate verbal. Às ironias do rei, responde o profeta com um desafio: no Monte Carmelo, em presença do povo, os sacerdotes de Baal e o profeta Elias hão-de invocar o poder do seu deus. Aquele que primeiro consumir a vítima sagrada com fogo será o Deus verdadeiro e enviará chuva sobre a sequiosa terra. Javé está com Elias e o povo, enfurecido, dá a morte aos falsos profetas.

(19) O episódio da morte de Acab vem repetido no Segundo Livro das Crónicas (18). 
Jezabel toma conhecimento do massacre e fica enfurecida; tomada de desvario, irrita-se com a sua congénita fragilidade e com a frouxidão de Acab:

"Ignaua leuium, o feminarum pectora,

Queis fortiores parca naturae manus

Inuidit artes, tela, loricam, tubam,

Largita lanam sordidam et inertem colum!

Nouerca dura, praegrauis, auara, inuida,

Vt dona sorte diuidis iniqua omnibus!

Fecisse tanti fuerat inuictum uirum,

Me Iezabelem feminam! Forsan comes

Sequerer ministros meque sequerentur ducem,

Vir quando nimium residet oblitus domi.

Nunc, eiulatum cogor indignum edere,

Irrisa, inulta, unius opprobrium senis,

Heu misera, nimium nupta patienti uiro."

"Ó corações brandos de mulheres sem audácia,

a quem a escassa mão da natureza quis privar dos ofícios vigorosos,

dos dardos, da couraça e da tuba militar,

e a quem deixou a lã mesquinha e a inábil peneira!

Madrasta cruel e dura, cobiçosa e inimiga,

Com que desigualdade tu repartes entre todos os teus dons!

Tão caro te foi criares invencível o homem,

E a mim, Jezabel, me criaste mulher?

Talvez eu pudesse ao menos ir na companhia dos meus servos,

E eles me seguissem como seu guia,

Já que em casa fica um homem assim tão fraco.

Mas agora tenho de fazer desaparecer esse indigno desgraçado,

Já que fui escarnecida, desonrada, pobre de mim,

Casada com um homem que tolera afrontas vindas de um velho.»(20)

(20) MARIA MARGARIDA LOPES DE MIRANDA, Miguel Venegas S. I. e o nascimento da tragédia jesuítica. A Tragoedia cui nomen inditum Achabus (1562), edição crítica, tradução, comentário e notas, Coimbra, 2002, pp. 466-467, II.03.900-912. Dissertação de doutoramento dactilografada. 
Estas suas palavras insinuam o retrato de um marido submetido aos caprichos da esposa. A ele naturalmente Miguel Venegas vai opor a imagem ideal da relação entre homem e mulher no casamento: a esposa submissa expõe-se às leis do marido (Leges subacta iam maritales subi) ${ }^{(21)}$, proclama o profeta Elias; mais à frente, acrescentará que aos maridos se impõe que dominem, ainda que pela força, a arrogância das suas esposas (Et arrogantes coniugum fastus manu) (22).

Representa esta rainha um papel pouco simpático, como vemos. Trata-se do símbolo da perdição do homem, que atinge o seu clímax quando os impropérios do profeta Elias a identificam com a doce serpente que impeliu a mão de Eva até ao fruto proibido, no paraíso(23). Embora a sua intervenção fique restrita à cena III (761-932), do Acto II (564-1201), nas palavras de Margarida Lopes de Miranda, "para o melhor e para o pior, a Jezabel criada por Venegas em 1562 foi assim a primeira e talvez a mais poderosa personagem feminina do teatro escolar do século XVI»(24).

Já na tragédia Saul Gelboeus ${ }^{(25)}$, que se inspira no Primeiro e no Segundo Livro dos Reis, que foi representada a 9 de Julho de 1559, durante as festas da Rainha Santa Isabel, havia sido dado um primeiro sinal das intenções de Venegas. Talvez se possa afirmar que a entrada em palco da Pitonisa, no Acto IV, tenha sido um ensaio premonitório.

A presença feminina na obra dramática do seu discípulo, Luís da Cruz, oferece-nos uma história semelhante. A tentativa mais ousada encontra-se na Iosephus, uma tragicomédia inspirada na história bíblica de José do Egipto,

(21) Achabus, I.01.161.

(22) Ibid., v.186. A mesma ideia é reiterada pelo seu servo, Abdias, mais à frente: "Cohibenda mentis ira feminae est uiris"; na tradução de Margarida Miranda: "Dos maridos é dever coibir as iras do ânimo feminino" (op. cit., p. 509).

(23) Vide Achabus, I.01.

(24) Miguel Venegas..., cit., p. 308.

(25) A Tragoedia Absalon, como demonstra Margarida Miranda, afinal não é de Miguel Venegas. A sua notoriedade explica que lhe tenham sido atribuídas peças bíblicas anónimas, como esta ou a comédia Tobias. Cf. ibid., p. 221. 
narrada no Génesis $(37-50)^{(26)}$, o primeiro livro da Bíblia e, portanto, do Pentateuco. José é o filho predilecto de Jacob (inter tuos / Fratres amore

primus $^{(27)}$, o primogénito de Raquel(28), que havia de morrer durante o parto de Benjamim(29).

Por causa do sonho da ceifa - que lhe concedia a primazia entre os seus irmãos - José tornou-se odiado pelos irmãos(30), que o venderam como escravo a uns comerciantes ismaelitas. Levado para o Egipto, foi revendido ao intendente do Faraó, Putifar. A perfídia da sua esposa arrastará José até aos calabouços egípcios.

Situa-se este episódio no início do Acto III, que abre com uma reflexão sobre os caprichos da fortuna. Na verdade, coube a Putifar por sorte (sors) e não pelos seus méritos (ob merita) este escravo distinto:

"Haud dubito, crediderim a caelo quaedam Bona

Quibusdam impertita esse, quae nec meruerint

Nec dii dedere ob merita, sed quia sors tulit.

Placuitque diuis, his potius quam illis dare.

Id longe apud me est factum testatissimum

Cuinam deorum meritus sum integerrimum

Mancipium, amore mei et fide clarissimum?

Temeraria est profecto res felicitas.

$V t$ caeci sunt eventus, ut ludibria

Fortunae, uel caeleste donum, industria

Nequaquam comparandam uel pecunia."

(26) Contudo, o argumento cénico não faz referência aos capítulos 38, 48, 49 e 50.

(27) Iosephus, I.01.264-265: " ...entre os teus / Irmãos, no amor o primeiro...”. Todas as citações são feitas a partir da edição crítica desta tragicomédia: ANTÓNIO MARIA MARTINS MElO, O P.e Luís da Cruz, S. J., e a tragicomédia Iosephus. Tomo II - Edição crítica, Braga, Faculdade de Filosofia, 2001. Dissertação de doutoramento dactilografada.

(28) Cf. Gen. 30, 22-24. Raquel era irmã de Lia, ambas filhas de Labão (Gen. 29, 16).

(29) Cf. Gen. 35, 16-20.

(30) No Coro do Anjos do Acto I, o Anjo da Guarda de José dirige-lhe estas palavras (Iosephus, I.Chor.916-918):

"... $\quad \ldots \quad \ldots$ casus

Plangis ne tuos, an fraternae

Scelus inuidiae nobile defles?»

... $\quad \ldots \quad \ldots$ as tuas desgraças

acaso choras ou porventura da fraterna

inveja, crime bem conhecido, é que te lamentas?» 
"Sem dúvida, estaria em crer que pelo céu alguns bens

a alguns foram concedidos, os quais nem o mereceriam

nem os deuses lhos deram pelos seus méritos, mas porque

[a sorte assim o quis.

E agradou aos deuses dar mais a uns do que a outros.

Isso há muito, para mim, é facto comprovadíssimo.

$\mathrm{Na}$ realidade, a qual dos deuses fui eu merecedor de tão perfeito

escravo, que tanto se distingue no amor e fidelidade para comigo?

Coisa bem caprichosa é de facto a sorte feliz!

Cegos são não só os acontecimentos fortuitos, como os caprichos

da fortuna, quer se trate de dádiva celeste, a diligência,

que não se deve comparar, quer se trate de dinheiro.»(31)

Comprado a uns árabes (Mihi uendiderunt Arabes seruum)(32), este escravo de aspecto nobre e de carácter modesto (forma et pudore ingenii) (33), em quem o intendente confia mais que nele próprio (sane illi fido magis quam mibi) ${ }^{(34)}$, é fonte de felicidade (sum beatus) ${ }^{(35)}$, pois que se revelou um excelente administrador na economia doméstica:

"Et sum beatus. Prandeo, ceno, accubo

Sine solicitudine quippe rem curat, domum

Moderatur unus, seruatque, mibi familiam:

Locupletat etiam. Fons honorum in aedibus

Perenitate clarus exundat meis.

Vnde nibil unquam gratius aut iucundius

Putiphar habebit, illum quam seruum sibi.»

"E sinto-me feliz. Almoço, janto, deito-me,

sem preocupações, pois cuida ele dos haveres,

sozinho dirige a casa e cuida da minha família:

e até a enriquece! Uma fonte clara de honras

na minha casa jorra permanentemente.

Daí que nada mais agradável ou mais aprazível

Putifar terá do que possuí-lo como escravo.»(36)

(31) Iosephus, III.01.1774-1784.

(32) Ibid., v. 1785.

(33) Ibid., v. 1786.

(34) Ibid., v. 1789.

(35) Ibid., v. 1790.

(36) Ibid., vv. 1790-1796. 
Este vínculo amistoso assume a natureza de vassalagem prestada pelo servo ao seu senhor, regida por princípios de fidelidade. Não é propriamente amizade, pois não se estabelece entre iguais e, por isso, não há liberdade. É a utilitas a determinar esta relação afectiva. Segundo Aristóteles, este é um exemplo de uma amizade imperfeita, que buscou o seu próprio interesse (Ética a Nicómaco, 1156 a 6-30). Por isso, não obstante o deslumbramento deste escravo virtuoso,

"Verum ipse mecum saepe miror cogitans

Quae tanta uirtus illa sit uel gratia

Vnius adolescentis erga caelites,

Vt quicquid ille dicat, recte dixerit,

Et quicquid ille faciat, recte fecerit.

Iurabo, nostrum diligit seruum Deus,

Et carus homini iure multo maximo est.

Fas est amare quos amant ipsi Dei.”

"Muitas vezes me ponho eu a admirar, pensando cá comigo mesmo, como há-de ser grande a virtude e a aceitação

deste adolescente para com os habitantes celestes.

Como tudo o que ele diz, está bem dito

e tudo o que ele faz, está bem feito,

hei-de jurar que Deus ama este nosso escravo

e é justamente muito querido ao homem.

É lícito amar aqueles que os próprios deuses amam.»(37)

É sobre ele que Putifar, sem hesitação, faz recair a acusação de atentado ao pudor da sua esposa. Depois de conversar com ela, regressa ao exterior da casa e profere estas palavras:

"Vbi ille qui me perdidit? Proh! Quid tibi

Ingrate reddam par sceleri tanto? Domum

Totam ne iuris esse permisi tui,

Vt crimen ausus pessimum deluderes?

Taces?

(37) Ibid., vv. 1797-1804. 
"Onde está aquele que me perdeu? Ah! O que é que te pagarei, ingrato, que seja proporcional a semelhante a tamanho crime? Permiti eu que tu estivesses em toda a casa como senhor dela para tu ousares ludibriar-me com crime tão hediondo? Tu calas-te?»(38)

As invectivas sobem de tom. Repentinamente, de homem mais amado, José transforma-se num monstro, aos elogios sucedem-se as acusações mais infamantes:

"...... ... PV. Culpa est mea.

Nam saepe monitus pauca mancipiis fore

Credenda, fidei cuncta commisi tuae.

En quo recidit istius illa sanctitas?

Simulata uirtus? Fraude tecta castitas?

Perfidia fuerat. Plorat: en ingenium, ea

Quoties fefellisti arte? Quae modestia

Oris pudici?

$« \ldots \ldots \quad$.... A culpa é minha.

Na verdade, muitas vezes fui avisado de que poucas coisas aos escravos deviam ser confiadas; confiei tudo à tua lealdade.

Vês no que veio a dar a santidade deste?

Seria virtude fingida? Castidade acobertada pela fraude?

Perfídia houve. Agora chora: eis a astúcia.

Quantas vezes enganaste com esta arte? Qual é a dignidade

dum rosto honesto?

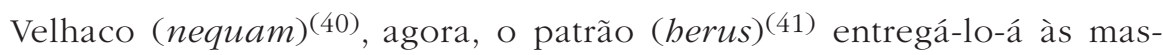
morras reais (in carcerem quo coercet rex suas custodias) ${ }^{(42)}$ :

"Properate, quaenam tanta uos tardat mora?

Eat in opacum carceris tetri specum

Ibi queratur teste se falso premi."

\footnotetext{
(38) Iosephus, III.03.1843-1847.

(39) Ibid., vv. 1848-1855.

(40) Ibid., vv. 1858.

(41) Ibid., vv. 1788.

(42) Ibid., vv. 1867-1868.
} 
"Apressai-vos! Que demora vem a ser essa?

Que vá para a caverna escura do lôbrego cárcere,

que aí se queixe de ser oprimido por falsas testemunhas.»(43)

José acaba de ser vexado publicamente, se bem que esteja inocente. E, contrariamente ao que seria de esperar, aceita o desfecho com resignação. É Cacodémon quem o confidencia ao espectador:

".... $\quad$... Doleo quod uadat lubens,

Quod non repugnet."

«..... Custa-me que vá com gosto, que não ofereça resistência.»(44)

A humildade aprende-se no exercício quotidiano ${ }^{(45)}$. Nas Constituições, constantemente se é interpelado a provas de humildade e de abnegação, pois do seu exercício advém a verdadeira humildade que, a par da caridade para com o próximo, e em particular para com a Companhia, há-de resplandecer no Prepósito Geral e torná-lo amável, tanto a Deus como aos homens ${ }^{(46)}$.

(43) Ibid., vv. 1890-1892.

(44) Ibid., vv. 1869-1870.

(45) No $6^{\circ}$ dia da Segunda Semana dos Exercícios Espirituais, Inácio de Loiola propõe ao exercitante, imediatamente antes da eleição, três maneiras ou modos de humildade "para a pessoa se afeiçoar à verdadeira doutrina de Cristo, nosso Senhor». São uma síntese da $1^{\text {a }} \mathrm{e}$ $2^{\mathrm{a}}$ Semanas, assim elaborada na pena do mestre jesuíta, António Freire: «1 $1^{\mathrm{a}}$ semana: ódio ao pecado, de maneira que nem por tudo o que é criado, se venha a deliberar em cometer um pecado mortal ou venial. Desejar, além disso, e escolher o que mais conduz ao fim para que fomos criados ( $1^{\circ}$ e $2^{\circ}$ graus ou maneiras de humildade). $2^{\text {a }}$ semana: escolher sempre o que Jesus Cristo escolheu, como o escolheu, e movido pelo amor ao mesmo Jesus Cristo $\left(3^{\circ}\right.$ grau de humildade)». ANTÓNIO FreIRE, Retiro espiritual, Braga, 1989, cap. 9 "Purgatório», pp. 74-84.

A eleição é o momento da escolha do estado de vida por que o exercitante há-de optar, tendo em vista o louvor de Deus e a salvação da alma. Há duas espécies de eleição - a eleição imutável (o matrimónio, o sacerdócio...) e a eleição mutável (tomar ou renunciar a bens temporais ou benefícios...) - , mas ambas convergem num fim último: a eleição da vida e da paixão de Jesus Cristo. INÁCIO DE LOIOLA, Exercícios Espirituais, tradução do autógrafo espanhol pelo P. ${ }^{\mathrm{e}}$ Vital Dias Pereira, Porto, ${ }^{2} 1983$, pp. 87-90, n. ${ }^{\text {os }} 169,171-174$.

(46) INÁCIO DE LOIOLA, Constituições da Companbia de Jesus, anotadas pela Congregação Geral 34 e Normas Complementares aprovadas pela mesma Congregação, Lisboa-Braga, 1997, p. 190, n. ${ }^{\circ} 725$. 
Para se alcançar a virtude da humildade e da abnegação(47) de todo o amor sensual e de toda a vontade e juízo próprio, o caminho para o conhecimento e amor de Deus( ${ }^{(48)}$, implica estar "pronto e decidido a aceitar e a sofrer pacientemente, com a graça de Deus, todas as injúrias, escárnios e opróbrios que andam associados à libré de Cristo Nosso Senhor, ou quaisquer coisas deste género, quer venham de alguma casa ou da Companhia (onde pretende obedecer nesta vida, humilhar-se e ganhar a vida eterna), quer de alguém de fora, não retribuindo a ninguém mal por mal, mas bem por mal» $(49)$.

José sofre pacientemente a humilhação de Putifar, sem resistência; de forma semelhante havia já recebido o opróbrio da escravidão.

Mas neste episódio, um dos grandes louros de José é a vitória da castidade ${ }^{(50)}$. Com efeito, resiste aos intentos da esposa de Putifar:

" $\ldots \ldots \ldots \quad \ldots \quad \ldots \quad$.... Illa pallium

Tenuit, reliqui fugiens; o ingens scelus!

Habeat. Pudorem malo seruare, ut uiri

Doceant mulieres iura sacrosancti tori.

Egone idoneus ad stuprum uisus? Mei

Mores ne facinus illud audendum, mibi

Prae se tulerunt? Quo expiabo flumine

Factum scelestae feminae? Iniecit manum,

Fugi, stetit animus integer, sed non fero

Polluta tactu. Pallium abripuit, sibi

Habeat, cremassem. Nile qui pleno alueo

Campis inundas, tolle te insolentius,

Me parte si qua polluit, fluctu ablue."

(47) A propósito, vide CARLOS PALMÉs DE GENOVER, S. J., La obediencia religiosa ignaciana, Barcelona, 1963; MANUEL MARIA ESPINOSA POLIT, S. J., La obediencia perfecta. Comentario a la carta de la obediencia de San Ignacio de Loyola, Quito, 1940.

(48) Ibid., p. 135, n. ${ }^{\circ} 516$.

(49) Constituições da Companhia de Jesus... cit., p. 43, n. ${ }^{\circ} 102$.

(50) O humanista italiano Paolo Vergerio, no seu tratado De ingenuis moribus et liberalibus studiis adolescentiae, também se refere à importância da castidade na juventude: "Bisogna badare perciò con somma cura che i giovanetti si mantengano soprattutto casti; infatti l'amore gustato anzitempo contamina anima e corpo. È dunque opportuno tenerli lontani dai balli e dagli spettacoli di simile genere, e così pure da eccessiva familiarità con donne...”. Apud E. GARIN, Educazione umanistica in Itália, Roma-Bari, 1975, p. 71. 
«..... $\quad \ldots \quad \ldots \ldots . .$. Ela o manto

me agarrou, deixei-lho, fugindo. Oh! que enorme crime!

Que fique com ele. A minha castidade prefiro conservar,

[para que os homens

ensinem às mulheres os direitos do sacrossanto leito nupcial.

Como é que eu lhe pareci idóneo para cometer adultério? Os meus

Costumes, porventura, terão mostrado diante de si que aquele crime

se devia tentar? Com que água hei-de purificar

a acção desta criminosa mulher? Lançou-me as mãos;

fugi; o meu coração permaneceu íntegro; mas não suporto

a poluição do seu tacto. Levou o manto, que fique com ele;

antes eu o tivesse queimado. Ó Nilo que com as tuas cheias

inundas os campos, levanta-te mais alto

se ela me poluiu com alguma parte, lava-me com as tuas águas.»(51)

Apesar de uma perfídia bem condimentada com as traquinices de Cacodémon, a inocência de José, espelha-a o seu rosto:

\section{Putiphar \\ Iosephe quid clamoris? Albes, pallidus \\ Cur ora muta?}

\section{IOS. Ora mutauit pudor.»}

Putifar

"Oh! José, que barulho é esse? Estás branco, pálido;

por que razão mudas o teu rosto?

José

O pudor mudou o meu rosto.»(52)

(51) Iosephus, III.02.1805-1817

(52) Ibid., vv. 1820-1821. Pelos trechos transcritos supra, José torna-se, assim, um exemplum do sucesso educativo prescrito pelos humanistas, com ecos também no tratado Famiglia de Leon Battista Alberti (1376-1422). As palavras que transcrevo são pronunciadas pelo principal interlocutor do diálogo, Lionardo: "- Non ti niego che i padri soprattutto, più che gli altri, debbono colle mani e co' piedi, con tutti i nervi, con ogni industria e consiglio, quanto possono, sforzarsi, che i figliuoli siano costumati ed onestissimi, sì perché fanno l'utile de' suoi (il costume in uno giovane non è meno che la ricchezza stimato), sì etiam perché rendono ornamento e pregio alla casa, alla patria sua ed a se stesso» (Apud E. GARIN, Educazione umanistica..., cit., p. 137). E não falta a exortação a um trato mais humanizado, neste calvário da educação - no dizer de Miguel Torga (Bichos — Contos, Coimbra, 131983, p. 16) - pois os filhos deviam ser levados, de preferência, pela razão: "E vogliono i fanciulli essere correcti con modo e ragione, e anche talora con severità: non vi si accanire però suso, come alcuni rocti e furiosi padri fanno; castigarli sanza ira, senza passione d'animo..." (Apud E. GARIN, Educazione umanistica... cit., pp. 153-154). 
Mas nem sempre a castidade saiu vitoriosa. Rúben manteve relações com Bilha, a concubina de seu pai, Jacob, que o veio a saber. Este ignominioso crime (turpe flagitium) deitou a perder o direito de progenitura(53). Judá há-de cometer incesto com a nora e tornar-se um pai infame (infamem patrem) (54). Contudo, a castitas era uma das virtudes a imitar pela mulher, como já verificámos em o De Institutione foeminae christianae, do humanista espanhol Juan Luís Vives (1492-1540)(55). Também a mensagem paulina é clara ao condenar as imoralidades na forma de incesto (I Cor. 5.1-5) e da fornicação (I Cor. 6.12-19).

Entre a devassidão que a tantos vence, qual farol se ergue a virtude de José, a sua pureza de espírito e de sentimentos, traduzida na recusa, até à prisão e mesmo até à morte, em se envolver com mulher alheia. De profundo significado são estas palavras proferidas pelo demónio que se revela incapaz de alcançar os seus intentos:

CACODAEMON

Nibil tamen mibi dari cupio, prae tua Anima, Iosephe. Posse credideram capi Amore dominae, restitit: castum piget Tentasse iuuenem, ne multi exemplum probent:

Et abstinere turpi a congressu uelint.

Qua re ditatur o reus et ditabitur

Magis quotidie, quippe fomentum rogi

Quo tartara ardent, est libido: plurium

Est illa domitrix sola, quam superbia,

Ira, gula, auaritia, inuidia, socordia, Septena quae sunt cornua quibus Lucifer

Et grex Auerni pallidi orbem uentilat."

(53) Iosephus, I.01.195-197.

(54) Iosephus, III.05.1916.

(55) Cf. JUAN LUÍS VIVES, The education of a Christian woman: a sixteenth century manual, Edited and Translated by Charles Fantazzi, Chicago \& London, 2000, p. 116. 


\section{CACODÉMON}

"(...) Para mim nada quero, senão a tua

alma, José. Julguei que podia deixar-se levar

pelo amor da senhora, mas resistiu. Envergonho-me

de ter tentado um jovem casto, pois muitos hão-de aprovar tal exemplo

e querer abster-se de relações torpes.

Oh! Com isto o réu é enriquecido e enriquecer-se-á

ainda mais quotidianamente, pois o que alimenta a fogueira

em que os infernos se consomem é a devassidão:

ela sozinha é mais dominadora do que a soberba,

a ira, a gula, a avareza, a inveja, a preguiça,

que são os sete chifres com que Lúcifer

e a grei do pálido Averno atormenta o mundo.»(56)

A luxúria é um dos vícios verberados por Dante, n'A Divina Comédia. A dissoluta rainha da Assíria, Semirâmis, encontrou-a Dante quando baixava ao segundo círculo, no Inferno, penalizada pela negra aura: «(..) foi a sabida / imperatriz de numerosas falas. / Em vício de luxúria tão rompida, / que o líbito fez lícito por lei, / contra a censura a que era conduzida.»(57). Seu mestre, Virgílio, havia ainda de nomear Cleópatra, a luxuriosa, e mais de mil sombras «a quem amor tirou da vida hostil» (58). No círculo oitavo se encontra outra famigerada mulher, a esposa de Putifar, "... a falsa que acusou José»(59).

A encerrar este acto, o coro, em verso sáfico, vai cantar a vitória de José sobre a luxúria, enaltecer o pudor sincero deste jovem, coluna de Israel e exemplum para as gerações vindouras:

"O pudor castae generose mentis,

Mentis o praeceps furor impudicae!

(56) Iosephus, III.05.1920-1931.

(57) Dante Alighieri, A Divina Comédia, tradução de Vasco da Graça Moura, Mem Martins, 1998 , p. 58 , vv. 54-57.

(58) Ibid., p. 60, v. 69.

(59) Ibid., p. 215, v. 97 
Quando iam mundo seniore tellus,

Prona laxarit uitiis habenas:

Dicet, o magnum iuuenem, periclo

Qui suo, uicit dominam pudore

Et lacessitus timuit iugalem

Rumpere nodum."

"Ó nobre pudor dum espírito casto!

Ó furor vertiginoso dum espírito impudico!

Quando a terra, já num mundo envelhecido,

der rédea solta aos vícios,

dirá: ó grande jovem, que com perigo

para a sua vida, venceu a senhora pelo pudor

e, provocado, temeu romper o laço conjugal!»(60)

É o canto triunfal da castidade, com raízes no Trionfo della castità, de Petrarca. A perseverança, o medo da infâmia e o desejo da honra e da pureza são virtudes cultivadas por este jovem que se celebrizaram neste triunfo ${ }^{(61)}$. É de novo a exaltação da temperantia, da modestia. Este triunfo simboliza ainda uma outra virtude, a fortitudo: forte na adversidade, teve ânimo suficiente na luta contra a intriga, para que a verdade fosse imposta. É a prática da temperança que conduz à morigeração nos costumes(62).

Semelhante atitude de José recorda-nos o usus aconselhado pelo Bispo de Silves: "A qualidade indispensável aos grandes frutos da honestidade é o desejo da glória (371.59-61) ${ }^{(63)}$, dentro dos limites da recta razão (367.32-40), a que se deve aliar o culto da vergonha (367.44-47), o medo da infâmia, o ódio à vilania (493.48-494.11). É tarefa dos educadores cultivar na alma dos seus discípulos o estímulo destes dois princípios (368.39-44)»(64).

(60) Iosephus, III.Cor.2481-2482; 2502-2507.

(61) Francesco Petrarca, Opere. Canzoniere, Trionfi, Familiarum Rerum Libri. Firenze, 1975, pp. 208-212, vv. 76-90 e v. 193.

(62) ARISTÓTELES, Ética a Nicómaco, 1105a 17-21.

(63) Neste sentido é interessante o passo do De gloria: H. OSORII Op. omnia, I, 122.47-52. Vide sobre este tema A. HAURY, "Cicéron et la gloire: une pédagogie de la vertu», in : Mélanges Boyancé. Paris, 1974, pp. 401-417.

(64) NAIR De NAZARÉ CASTRO SOARES, O Príncipe ideal no século XVI e a obra de D. Jerónimo Osório, Coimbra, ${ }^{2} 1999$, p. 428. 
A castidade é um tema que a mitologia consagrou no desenlace trágico do herói Hipólito, vítima da infâmia de Fedra, que o acusa a Teseu, seu esposo: o assunto seria imortalizado na Phaedra de Séneca, que já havia sido glosado por Eurípides (Hipólito, 429 a. C.).

A par da virtude da castidade, emerge, como vimos, um tema fundamental, a defesa do matrimónio, ou do $7^{\circ}$ sacramento, como the chamou Erasmo (Enchiridion septimum sacramentum), em defesa dos valores morais. A primeira expressão do amor familiar decorre da relação entre marido e esposa.

Como sabemos pela história bíblica, Jacob desposou duas mulheres — as irmãs Lia e Raquel - e as suas duas escravas, Zilpa e Bilha, respectivamente. De ambas as escravas teve filhos, mas por razões de ausência de fecundidade, no caso de Lia, e de esterilidade, no caso de Raquel: assim se tornaram mães por intermédio das criadas, pois a esterilidade era um grande opróbrio para a mulher casada. Com efeito, era interpretado como castigo de Deus. Já assim havia acontecido, no passado, com o patriarca Abraão que concebeu Ismael da escrava egípcia Agar (Gen. 16.2). A bigamia, a poligamia ou a sua forma mitigada no concubinato são práticas entre os povos vizinhos e toleradas entre os israelitas. Mas o ideal da família monogâmica já nos é proposto no Génesis (2.23-24). Neste particular, assume especial significado, nas Sagradas Escrituras, o Cântico dos Cânticos, poema atribuído ao rei Salomão. Prefigura-se aqui a aliança de Deus-esposo com Israel-esposa, à luz do Antigo Testamento; à luz da revelação cristã, configura o "matrimónio" da Nova Aliança, a união mística de Jesus Cristo com a Sua Igreja. São Paulo, na Carta aos Efésios (5.22-33), actualiza esta mensagem à luz de Cristo, renovando o apelo de fidelidade mútua no casamento.

O Iosephus, num contexto de diálogo entre várias culturas e povos, faz apelo à castidade no casamento, como vimos no episódio da esposa de Putifar. Serve ainda este exemplo para condenar a poligamia, frequente entre os povos indígenas. Acresce, ainda, o exemplum de Jacob. Em pleno Egipto, presos pelo grande senhor, Judá esclarece o pai que o governador 
"Existimauit perduelees, liberos

Vnius esse nos parentis diximus."

«julgou-nos inimigos

e nós dissemos que éramos filhos de um só pai.» (65)

A mulher de Putifar, como sabemos, não se mostrou ao público, isto é, não entrou em cena, mas podia estar em palco, embora protegida pelo cenário. Também ela revela uma notória ascendência sobre o marido, que acaba ridicularizado, pois se deixou seduzir pela destreza feminina. Não obstante este papel recatado aos olhos do público, a presença feminina torna-se determinante na economia da narrativa. Com efeito, a desordem que se abateu sobre a casa de Putifar, aliada à interpretação, com verdade, por influição divina, dos sonhos do padeiro e do copeiro, levam ao reconhecimento das suas virtudes junto do carcereiro, que o vai nomear prefeito da prisão. O copeiro, que havia sido restituído às suas antigas funções, vai aconselhá-lo ao Faraó. De facto, as visões de que padecia não as decifraram satisfatoriamente os áugures egípcios. Deste modo, em sinal de reconhecimento, o primogénito de Raquel vai ser nomeado Administrador do Egipto. Providencial este cargo, pois assim vai salvar a sua família do extermínio certo, às garras de uma fome que se estendia a todo o globo terrestre.

Quatro anos antes, Luís da Cruz já havia feito uma primeira tentativa para introduzir um papel feminino, na tragédia Sedecias, também de inspiração bíblica, essencialmente no Livro de Jeremias do Antigo Testamento(66). Estamos a falar da mãe de Sedecias, a Amital. Precisamente oito anos depois de Mestre Venegas incluir uma figura feminina no enredo da tragédia Achabus, como vimos acima.

(65) Cf. V.02.3248-3249.

(66) Para mais pormenores, vide MANUEL JOSÉ DE SOUSA BARBOSA, Bíblia e tradição clássica: a tragédia Sedecias do P. Luís da Cruz, S. I., na convergência de uma estética e de uma pedagogia. Dissertação de doutoramento dactilografada. Tomo I - Estudo Literário. História do texto e critérios ecdóticos. Lisboa, 1998, p. 67. 
Esta data revela-se importante, pois estamos num tempo em que não se acha indecoroso a introdução de donzelas ou rainhas na representação de tragédias ${ }^{(67)}$. Desta opinião é o crítico e pedagogo messanense Giovanni António Viperano (1535-1610) que, por esta altura, quando ainda pertencia à Companhia de Jesus, havia de escrever o tratado De poetica libri III.

Esta mentalidade havia de ser contida, pela primeira vez, na Ratio de 1586, ao proibir-se a presença de figuras femininas em palco, excepto nas províncias transalpinas ou se os costumes locais o exigirem(68). Tenhamos presente que nestas representações teatrais tomavam parte apenas actores masculinos, ainda que os papéis fossem femininos. E mesmo entre os espectadores não era bem-vinda a presença feminina (69). A versão definitiva da Ratio atque Institutio Studiorum Societatis Iesu, em 1599, proibiria, definitivamente, a presença feminina no âmbito dos concursos dramáticos ${ }^{(70)}$. Mas não foi acatada da mesma forma em todas as províncias, como sucedeu numa das províncias da Alemanha. Invocando o princípio de adaptação aos tempos e lugares ${ }^{(71)}$, o P. Geral Cláudio Acquaviva concede-lhe regime de excepção, desde que fossem personagens femininas graues et modestiae ${ }^{(72)}$.

O espírito desta regra já se pressentia nas Constituições, redigidas por Inácio de Loiola e aprovadas na 1. ${ }^{\text {a }}$ Congregação Geral da Companhia de

(67) Ioannis Antonii Viperani De Poetica Libri Tres, Antuerpiae, ex officina Christophori Plantini, Architypographi regii, MDLXXIX, p. 99: Ne censemus indecore puellas et reginas induci, cum res grauis in augusto loco agatur. Cf. MANUEL JOSÉ DE SOUSA BARBOSA, Bíblia e tradição clássica..., cit., p. 30.

(68) Cf. Ratio Studiorum 1586/B, in: Monumenta Paedagogica Societatis Iesu, vol. 5, Roma, 1986, p. 205.

(69) Vide, a propósito, a carta de Baltasar Barreira que dá notícia da representação de uma tragédia por ocasião da inauguração da Universidade de Évora, a 1 de Novembro de 1559. Litterae Quadrimestres ex universis praeter Indiam et Brasiliam locis in quibus aliqui de Societate Iesu versabantur Romam missae, Vol. 6, Madrid - Roma, 1928, p. 312. Cf. MARIA MARGARIDA LOPES DE MIRANDA, Miguel Venegas..., cit., p. 309.

(70) Cf. Monumenta Paedagogica Societatis Iesu, vol. 5, Roma, 1986, p. 371.

(71) Cf. INÁCIO DE LOIOLA, Constituições da Companhia de Jesus anotadas pela Congregação geral 34 e Normas Complementares aprovadas pela mesma Congregação, Braga, 1997, pp. 103 e 123, n. ${ }^{\text {os }} 351$ e 462 .

(72) Cf. F. Charmot, S. J., La pédagogie des Jésuites, Paris, 1951, p. 242. 
Jesus em 1558, onde se apelava aos Superiores para que não permitissem, aos jovens, a leitura de livros que ofendessem os bons costumes. Na sequência desta proibição, menciona-se o nome de Terêncio, o único autor clássico identificado(73), pois, segundo ele, nas aulas, que houvesse, enfim, a preocupação de lhes incutir hábitos dignos de cristãos ${ }^{(74)}$. Trata-se de integrar, em termos inacianos, "virtude e letras, vida e ciência, conduta e saber» $(75)$.

Mas nem sempre estes princípios rigorosos se observaram. As antologias dos Jesuítas, que sobrevalorizaram a castidade, não deixam de acolher frases que nos podem surpreender, como esta da comédia plautina Stichus, claramente na defesa dos direitos da mulher; são palavras que saem da boca de Pânfila, opondo-se, deste modo, aos caprichos paternos:

"Stultiast, pater, uenatum ducere inuitas canes.

Hostis est uxor inuita quae uiro nuptum datur."

"É uma insensatez, pai, mandar as cadelas caçar contra vontade.

Uma mulher casada sem o seu consentimento é uma inimiga

para os maridos.» $(76)$

(73) INÁCIO DE LOIOLA, Constituições da Companbia de Jesus..., cit., p. 124, n. ${ }^{\circ}$ 469: "Se alguns, como Terêncio, não puderem de modo algum ser expurgados, mais vale não se lerem, para que a natureza dos assuntos não ofenda a pureza dos corações».

(74) Ibid., p. 126, n. ${ }^{\circ} 481$.

(75) José MANUEl MARTins LOPES, Projecto Educativo da Companhia de Jesus: Dos Exercícos Espirituais aos nossos dias, Braga, 1997, p. 100. Cf. INÁCIO DE LOIOLA, Constituições da Companbia de Jesus..., cit., p. 124, n. ${ }^{\circ} 307$.

(76) Plauto, P, vv. 137-142, citado por AgOSTINHO DE JESUS DOMINGUES, Os clássicos latinos nas antologias escolares dos jesuitas nos primeiros ciclos de estudos pós-elementares no século XVI em Portugal, Porto, 2002, p. 214. Dissertação de doutoramento dactilografada. Agostinho Domingues, no entanto, não deixa de chamar a nossa atenção para o pensamento misógino da Companhia a propósito da alteração dos versos 121 e 122 desta comédia. Com efeito, enquanto ali se pode ler este diálogo entre Antifão e Pânfila ("AN. Qui potest mulier uitare uitiis? PAM. Vt cottidie / Pridie caueat ne faciat quod pigeat postridie»: "AN. Como pode uma mulher evitar os seus defeitos ? PAM. Evitando em cada dia fazer o que, no dia seguinte, lamentará ter feito.»), na antologia a deturpação desta passagem é evidente, havendo um só interlocutor ("Qui potest uitare, uitet: ut cottidie / Pridie caueat, ne faciat quod pigeat postridie»: "Quem pode evitar as mulheres, evite-as: de modo a precaver-se a tempo para não fazer aquilo de que possa vir depois a arrepender-se».). Cf. Plaute, Comédies, T. VI (Pseudolus, Rudens, Stichus), Paris, 1972, pp. 220-221. 
Nesta linha agiu Inácio de Loiola ao fundar, em Roma, a Casa de Santa Marta, que se destinava a acolher mulheres casadas ou que pensavam abraçar a vida matrimonial, libertando-as de uma vida de prostituição. Inspirando-se na Vida de S. Ignacio de Loyola do jesuíta espanhol Pedro Ribadeneira (1527-1611) ${ }^{(77)}$, o biógrafo francês Hercule Rasiel da Silva, autor em 1736 de uma História do admirável Dom Inigo de Guipuzcoa(78), evoca, deste modo, a experiência do fundador da Companhia:

"Foi ele o primeiro a contribuir para a construção dessa Casa. A exemplo dele, muitos senhores e damas da mais alta categoria forneceram grandes somas de modo que em pouco tempo se erigiu um grande edifício onde se instalou essa espécie de arrependidas... Ele próprio ia buscar as raparigas de vida fácil para as levar para lá e não corava por aparecer na cidade no meio de um grupo dessas criaturas. Diziam-lhe por vezes que perdia o seu tempo e que aquelas infelizes estavam demasiado endurecidas pelo pecado para o deixarem definitivamente. 'Mesmo que eu só as impeça de ofender a Deus por uma noite, dou o meu sacrifício por bem empregado: e não o lamentarei mesmo quando tiver a certeza de que elas regressam no dia seguinte ao seu comércio infame'.»(79)

A esta havia de juntar-se a Casa de Santa Catarina, destinada às filhas das prostitutas. O testemunho contemporâneo do português P. Bartolomeu Ferrão, exarado em carta de 12 de Abril de 1546, que dirigiu a Simão Rodrigues, dá conta do empenho do Geral da Companhia nesta obra:

«Nestas coisas que aqui muitas vezes acontecem leva não pequeno trabalho nosso Padre, tirando raparigas das suas casas, onde viviam com mulheres de má vida, de cujos exemplos o inimigo se podia servir, e colocando-as em lugares seguros, aprovados por Sua Santidade, de maneira que fiquem livres de perigo.» (80)

(77) Fontes Narrativi de S. Ignatio de Loyola et de Societatis Iesu initiis, ed. de Candidus de Dalmases, IV, Romae, 1965, p. 411.

(78) HERCUle RASIEl DA SILVA, Histoire de l'admirable Dom Inigo de Guipuscoa, La Haye, 1736.

(79) Citado por JeAn Lacouture, Os Jesuitas... cit., p. 132.

(80) Monumenta Ignatiana ex autographis vel ex antiquioribus exemplis collecta. Sancti Ignatii de Loyola Societatis Isesu fundatoris epistolae et instructiones, I, Madrid, 1903, p. 373; 
E se o espírito inaciano se revela, na praxis, tão contrário a tal espírito antifeminista, idêntica atitude nos transmitem as Sagradas Escrituras. Um dos testemunhos mais frequentemente invocados para desvalorizar a imagem da mulher é o capítulo terceiro do primeiro livro da Bíblia, o Génesis, versículos um a treze, passagem que tradicionalmente atribui à mulher a introdução do pecado no mundo. Acresce ainda que no capítulo anterior se narra a criação da mulher a partir da costela que Deus havia retirado ao homem (Gén. 2, 18-22), no contexto de um relato da criação, segundo a tradição Javista, em linguagem popular, à maneira de uma fábula: «uma narração mítica que interpreta a vida humana em determinado tempo histórico, apreendendo a realidade da vida de forma simbólica, porque uma narração artística resiste às vicissitudes do tempo e do espaço de modo mais consistente do que qualquer outra»(81).

A esta luz se compreende a reinterpretação do texto genesíaco 4b-3,24 por Armindo dos Santos Carvalho que, apoiada mormente no confronto com textos coevos do Médio Oriente, elimina do "mito adâmico» toda a sombra de pecado no sentido tradicional cristão ${ }^{(82)}$. Daqui resulta uma atitude de dignificação da mulher, como parece perscrutar-se nas palavras do sacerdote carmelita: «redescoberta na sua natureza literária de 'mito de origem', a narração deixa de ser instrumentalizada para inspirar ou legitimar teorias e práticas de poder, como lhe aconteceu em diversas interpretações pela cultura ocidental, e desprende de novo a sua força genuína e espiritualidade própria»(83).

CÂNDIDO De DALMaSES, S. J., Inácio de Loyola, fundador da Companhia de Jesus, Porto - São Paulo, 1984, p. 166. Neste contexto talvez ganhe importância recordar que Inácio de Loiola, na sua juventude, teve uma filha, Maria de Loiola, que havia de ocultar a sua paternidade sob o nome de Maria de Villareal. Cf. ROMEO DE MAIO, "Ignazio di Loyola e la donna", in: QUINTIN ALDEA (ed.), Ignacio de Loyola en la gran crisis del siglo XVI, Congreso Internacional de Historia (Madrid, 19-21 noviembre de 1991), Bilbao y Santander, 1993, p. 284

(81) JESÚs HERRERO, «O «Mito Adâmico» e a vida humana num livro de Armindo dos Santos Vaz - Um exercício da «razão vital e histórica» (II), Brotéria, 143 (1996) 588; AGOsTinHo DE Jesus Domingues, Os clássicos latinos nas antologias escolares dos jesuítas..., cit., pp. 408-409.

(82) Ibid., p. 599.

(83) ARMindo dos SANTOS VAZ, A visão das origens em Génesis 2, 4b-3,24, Lisboa, 1996, p. 461. 
Outros textos do Novo Testamento confirmam a dignificação da mulher. Na carta que São Paulo dirige aos cristãos de Colossos (Cl. 3,18-19), pode

ler-se: "Esposas, sede submissas aos maridos, como convém ao Senhor. Maridos, amai as vossas esposas e não vos exaspereis contra elas»(84). A afirmação da igualdade em Cristo já está inscrita num dos primeiros textos paulinos, a carta aos Gálatas (3.28): "Não há judeu nem grego; não há escravo nem livre; não há homem e mulher porque todos sois um só em Cristo Jesus» ${ }^{(85)}$.

(84) Bíblia Sagrada, para o terceiro milénio da encarnação, versão dos textos originais sob a direcção de Herculano Alves, Lisboa, Difusora Bíblica, 2003, p. 1935. Na Carta aos Efésios (Ef. 5, 24-25, 28 e 33), que hoje parece certo tratar-se de uma circular paulina enviada aos cristãos da Ásia Menor, também se encontram frases animadas pelo mesmo espírito: "Ora como a Igreja se submete a Cristo, assim as mulheres, aos maridos, em tudo. Maridos, amai as vossas mulheres, como Cristo amou a Igreja e se entregou por ela... Assim devem também os maridos amar as suas mulheres, como o seu próprio corpo. Quem ama a sua mulher, ama-se a si mesmo... cada um ame a sua mulher como a si mesmo; e a mulher respeite o seu marido". Ibid., pp. 1921-1922.

(85) Ibid., p. 1911. 
(Página deixada propositadamente em branco) 


\section{Série}

\section{Documentos}

Imprensa da Universidade de Coimbra

Coimbra University Press

2006

- $\mathrm{U}$

C • 